OPEN ACCESS

Edited by:

Gilles Benichou,

Massachusetts General Hospital,

USA

Reviewed by:

Nuala Mooney,

Centre National pour la Recherche

Scientifique, France

Régis Josien,

Nantes University Medical School,

France

*Correspondence:

Angus W. Thomson

thomsonaw@upmc.edu

Specialty section:

This article was submitted to Alloimmunity and Transplantation,

a section of the journal

Frontiers in Immunology

Received: 28 October 2015 Accepted: 12 January 2016

Published: 28 January 2016

Citation:

Thomson AW, Zahorchak AF, Ezzelarab MB, Butterfield $L H$, Lakkis FG and Metes DM (2016)

Prospective Clinical Testing of Regulatory Dendritic Cells in Organ

Transplantation.

Front. Immunol. 7:15.

doi: 10.3389/fimmu.2016.00015

\section{Prospective Clinical Testing of Regulatory Dendritic Cells in Organ Transplantation}

\author{
Angus W. Thomson 1,2*, Alan F. Zahorchak', Mohamed B. Ezzelarab ${ }^{1}$, Lisa H. Butterfield ${ }^{2,3}$, \\ Fadi G. Lakkis ${ }^{1,2}$ and Diana M. Metes ${ }^{1,2}$ \\ ${ }^{1}$ Department of Surgery, Starzl Transplantation Institute, University of Pittsburgh School of Medicine, Pittsburgh, PA, USA, \\ ${ }^{2}$ Department of Immunology, University of Pittsburgh School of Medicine, Pittsburgh, PA, USA, ${ }^{3}$ Department of Medicine, \\ University of Pittsburgh School of Medicine, Pittsburgh, PA, USA
}

Dendritic cells (DC) are rare, professional antigen-presenting cells with ability to induce or regulate alloimmune responses. Regulatory DC (DCreg) with potential to down-modulate acute and chronic inflammatory conditions that occur in organ transplantation can be generated in vitro under a variety of conditions. Here, we provide a rationale for evaluation of DCreg therapy in clinical organ transplantation with the goal of promoting sustained, donor-specific hyporesponsiveness, while lowering the incidence and severity of rejection and reducing patients' dependence on anti-rejection drugs. Generation of donor- or recipient-derived DCreg that suppress T cell responses and prolong transplant survival in rodents or non-human primates has been well-described. Recently, good manufacturing practice (GMP)-grade DCreg have been produced at our Institution for prospective use in human organ transplantation. We briefly review experience of regulatory immune therapy in organ transplantation and describe our experience generating and characterizing human monocyte-derived DCreg. We propose a phase I/II safety study in which the influence of donor-derived DCreg combined with conventional immunosuppression on subclinical and clinical rejection and host alloimmune responses will be examined in detail.

Keywords: dendritic cells, immune regulation, renal transplantation

\section{INTRODUCTION}

While rates of acute renal transplant rejection have improved dramatically since the advent of calcineurin inhibition $(\mathrm{CNI})>30$ years ago, similar improvement in long-term graft survival has not been achieved. This reflects the inability of conventional immunosuppressive agents to prevent late graft dysfunction leading to transplant failure $(1,2)$. Moreover, conventional immunosuppression is associated with significant morbidity and mortality due to cardiovascular, infectious, and pro-neoplastic side effects. Attempts to improve long-term survival, while reducing the burden of immunosuppression, have not been particularly fruitful to date. While the recent introduction of co-stimulation blockade, although renal-sparing, has resulted in an increased incidence of acute rejection (3), use of depleting antibody $(\mathrm{Ab})$ as induction therapy at the time of transplantation has also failed to guarantee safe withdrawal of CNI, even in patients with stable graft function $(4,5)$. Furthermore, efforts to induce donor-specific tolerance using hematopoietic stem cell transplantation, an approach first shown to be successful many years ago in mice (6), have yielded promising 
results, but many hurdles remain in terms of safety and widespread applicability (7).

Our long-term goal is to develop a novel, safe, donor-specific induction (pre-conditioning) approach that will promote sustained, donor-specific immune hyporesponsiveness, while lowering the incidence and severity of acute and chronic rejection and reducing patients' dependence on anti-rejection drugs. There is recent evidence that, by exploiting inherent mechanisms of immune regulation, it may be possible to achieve this goal. Rare, naturally occurring regulatory immune cells, either innate [regulatory dendritic cells (DCreg)] or adaptive [regulatory $\mathrm{T}$ cells (Treg)], critically regulate immunity, can promote antigen (Ag)-specific $\mathrm{T}$ cell hyporesponsiveness, and prevent adverse immune reactions (self-tolerance) in the healthy steady-state $(8,9)$. Moreover, in small animals, the adoptive transfer of DCreg (10-13) or Treg (14) can prolong allograft survival and induce donor-specific tolerance to organ transplants (15). Other regulatory immune cells with potential therapeutic applications include regulatory macrophages [Mreg; (16-18)], myeloidderived suppressor cells [MDSC; (19)], T regulatory type-1 cells [Tr1 cells; (20)], and regulatory B cells (21). In addition to ex vivo-expanded Treg, now entering phase I/II trials in organ transplantation ${ }^{1}$, a compelling rationale has emerged for clinical testing of DCreg, i.e., donor or recipient blood monocyte-derived DC generated and modified ex vivo to promote their inherent regulatory properties $(13,22-24)$. Thus, we and others have shown that, in rodents, infusion of DCreg of donor or recipient origin before or after transplantation, including their use in combination with conventional immunosuppressive agents, can promote indefinite organ allograft survival. More importantly and uniquely, using a robust, clinically relevant, non-human primate (NHP) model with minimal immunosuppression, we have shown that infusion of donor-derived DCreg, 1 week before transplant, safely prolongs major histocompatibility complex (MHC)-mismatched, life-sustaining renal allograft survival, with no evidence of host sensitization (25). Equally significant is our demonstration that this therapeutic effect is associated with selective attenuation of donor-reactive memory $\mathrm{T}$ cell (Tmem) responses $(25,26)$, an important barrier to improvement of long-term graft survival $(27,28)$.

We have now generated good manufacturing practice (GMP) grade human DCreg from elutriated peripheral blood monocytes and demonstrated both their stable resistance to maturation under inflammatory conditions and their ability to negatively regulate alloreactive $\mathrm{T}$ cell responses. We have also established release criteria for clinical testing and plan to conduct a safety trial of donor-derived DCreg in adult, de novo, live-donor renal transplantation. To our knowledge, this promising donor-specific induction approach to regulatory immune cell therapy in clinical organ transplantation is unique. It is distinct from the testing of recipient blood monocyte-derived DCreg in live-donor renal transplantation currently being conducted at the University of Nantes, France, as part of The ONE Study $(29,30)$.

${ }^{1}$ https://clinicaltrials.gov

\section{THE CASE FOR DCreg THERAPY IN ORGAN TRANSPLANTATION}

Extensive pre-clinical studies that we and others have conducted in rodents and human surrogate models provide compelling evidence of the potential of regulatory immune cell therapy to improve allograft outcomes and, in many instances, promote donor-specific tolerance (15). The case for testing DCreg generated ex vivo in human transplantation is particularly compelling $(13,23,24)$ for the following reasons. First, DC are uniquely wellequipped, professional Ag-presenting cells (APC) that potently regulate innate and adaptive immunity $(31,32)$. Second, in many animal studies, DCreg adoptively transferred to graft recipients before transplant induce Ag-specific T cell unresponsiveness (13) and promote indefinite organ allograft survival. Moreover, this beneficial effect on graft survival does not appear to depend on the in vivo persistence of intact DCreg (33-35). Indeed, the apparent independence of efficacy and regulatory mechanisms on the persistence of intact donor DCreg may be a distinct advantage over other cell therapy approaches. Thus, e.g., Treg therapy may require costly repeated infusion of very large numbers of expanded cells $(36,37)$ and their sustained viability/replication may be required to achieve a therapeutic effect. Third, an important attribute of DCreg is their ability to regulate, in addition to de novo-primed effectors, preformed Tmem responses (38-40) that, either due to preformed memory to alloAgs or due to molecular mimicry and cross-reactivity with human leukocyte antigens (HLA) (41), represent a major barrier to long-term graft survival in humans (27, $28,42,43)$. Fourth, in normal humans, local adoptive transfer of monocyte-derived DCreg has been shown to induce Ag-specific unresponsiveness to nominal Ags $(44,45)$. Fifth, using minimal immunosuppression in a robust NHP model, we have reported that a single infusion $\left(3.5-10 \times 10^{6} / \mathrm{kg}\right)$ of donor-derived DCreg, 1 week before transplant, safely prolongs renal allograft survival, with no evidence of host sensitization (25). Importantly, this effect is associated with attenuation of donor-specific, alloreactive Tmem responses $(25,26)$.

The unique phase I/II trial of donor-derived DCreg that we now propose in live-donor renal transplantation is essentially a dose-escalation safety trial in which the cell product will be administered, once only, concomitant with mycophenolic acid (MPA), 1 week before transplantation to patients receiving standard immunosuppression (CNI, MPA, and steroids). Successful safety evaluation of our strategy and any evidence of inhibition of early, acute subclinical or clinical rejection, and/or attenuation of long-term anti-donor immunity would justify broader evaluation of DCreg efficacy in renal transplantation. This would potentially address unmet needs of CNI-free immunosuppression and/or realize the unmet goal of improving long-term allograft survival, without increasing the burden of immunosuppression.

Thus, in future studies, it would be of interest to evaluate the influence of DCreg combined with co-stimulation blockade (Co-B) to ascertain whether the incidence of rejection episodes encountered with Co-B (3) can be reduced. Furthermore, evidence of a beneficial effect of DCreg pre-conditioning in early clinical trials might justify evaluation of immunosuppressive drug curtailment. It is likely that the DCreg approach can be 
applied readily in the clinic since, based on pre-clinical testing, a single infusion of a relatively small number of DCreg is sufficient to achieve the salutary effect. Therefore, neither expensive expansion of the cell product, nor repeated infusion may be necessary. It is also probable that donor-derived DCreg will have broader clinical applications to encompass recipients of renal and other organ transplants from deceased donors. Indeed, rodent studies have shown that delaying DCreg infusion until 7 or 14 days post transplant is (still) effective in prolonging graft survival $(46,47)$, thus providing ample time to prepare DCreg from deceased donors.

\section{NOVELTY OF THE APPROACH}

Several closely interrelated aspects of our proposed clinical trial of DCreg in live-donor renal transplantation are highly innovative. First, we have generated a highly-purified GMP cell product (allograft donor blood monocyte-derived DCreg) distinct from those [autologous tolerogenic DC (not pulsed with donor antigen), Treg, Type-1 regulatory T cells ( $\operatorname{Tr} 1)$ cells, Mreg, and mesenchymal stem cells] being investigated by other groups, which satisfies phenotypic and functional release criteria. The manufacturing process is relatively simple, comparatively short and highly reproducible. Second, while early pilot studies have begun to examine the safety of autologous DCreg in human autoimmune diseases (48-50) and organ transplantation (29), this will be the first study to test allogeneic (donor-derived) DCreg in human organ transplantation. Third, our proposed mechanistic studies will address our hypothesis that, in addition to inhibition of de novo $\mathrm{T}$ cell priming and memory reactivation against donor HLA Ags, DCreg infusion will selectively undermine early inflammation that fuels anti-donor effector/Tmem responses and promote specific $\mathrm{T}$ cell unresponsiveness to donor that we will monitor sequentially in blood and protocol biopsies. We will also generate novel insight into the persistence/longevity of donor-derived DCreg in graft recipients. Of particular relevance, based on our NHP transplant data, will be analyses of de novo-primed T cell and Tmem phenotype and function and the potential of establishing new biomarkers of donor-specific hyporesponsiveness based on the profile of donor-reactive T cells. Fourth, since protocol biopsies will be performed, we will gain preliminary insight into the influence of DCreg on the incidence of subclinical rejection, an important predictor of long-term graft outcomes by analyzing graft-infiltrating T lymphocytes. By contrast, traditional immunosuppression trials have focused on the incidence of clinically evident rejection as a principal endpoint.

\section{RATIONALE FOR TESTING DCreg IN HUMAN KIDNEY TRANSPLANTATION}

Dendritic cells are highly specialized, bone marrow-derived APC [first described $>40$ year ago (51)] that induce or regulate innate and adaptive immunity $(13,32,52-54)$. While DCreg play a crucial role in maintaining self-tolerance in the healthy steady-state $(8,55,56)$ over the past 20 year, our research and others have revealed that these cells can subvert naïve $\mathrm{T}$ cell and Tmem responses by various mechanisms $(13,22,57-59)$ and that
DCreg can induce or restore $\mathrm{T}$ cell tolerance in animal models of autoimmune disease (60-63) or organ transplant rejection (12, $13,22,64)$. In experimental transplantation, both donor-derived allogeneic DCreg and donor Ag-pulsed host autologous DCreg are effective. Importantly, our work has also confirmed that adoptive transfer of donor-derived DCreg can safely regulate $\mathrm{T}$ cell responses in clinically relevant NHP models, including MHC mis-matched organ allograft recipients $(25,65)$, an important bridge to clinical testing. There is also well-documented evidence that adoptive transfer of DCreg (in vitro-generated autologous DC) via local administration can control $\mathrm{T}$ cell responses to model Ags (flu matrix peptide and keyhole limpet hemacyamin) in human healthy volunteers $(44,45)$. Important insights gained from in vitro studies and animal models have driven the recent development of clinical grade human DCreg (66-70), with the potential to treat autoimmune disease or enhance transplant survival, while reducing patients' dependence on immunosuppressive drugs. Phase I safety trials, in which autologous DCreg have been administered locally, have been conducted in type-1 diabetes (48) and rheumatoid arthritis (RA) $(49,50)$, with results that emphasize the feasibility, safety, and potential efficacy of DCreg therapy.

Based on these findings, we hypothesize that DCreg infusion, as an adjunct to conventional immunosuppression, can improve long-term renal allograft and patient outcomes, with minimal early adverse events, by targeting both innate immunity and preformed memory responses. It also carries the prospect of enabling immunosuppression reduction in stable patients or converting to CNI-free immunosuppression, without increasing the incidence of rejection.

Our laboratory has had a major focus on the characterization and therapeutic efficacy of DCreg, especially in experimental pancreatic islet, skin, and organ transplantation (46, 64, 71-79). These studies include the first observations that these regulatory innate immune cells, deficient in MHC and co-stimulatory molecule expression and in the production of pro-inflammatory cytokines, could subvert alloAg-specific T cell responses, in vitro and in vivo $(72,80)$. In addition, we have extensive experience in the characterization and immune profiling of human T lymphocytes, including the contribution of naïve $\mathrm{T}$ cell and Tmem subsets to the alloimmune response, and the effects of induction therapy on regulatory $\mathrm{T}$ cell and Tmem subsets in relation to clinical outcome in kidney transplantation $(41,81)$.

\section{EVIDENCE IN SUPPORT OF DCreg THERAPY IN TRANSPLANTATION}

We summarize below evidence from rodent, NHP, and human studies that support the safety and, in the case of pre-clinical models, the efficacy of DCreg in solid-organ transplantation.

\section{Rodent Observations}

We and others have shown that combination of pre-transplant (day -7 ) infusion of donor-derived DCreg, either alone or with low doses of immunosuppressive agents, can induce donor-specific organ transplant tolerance in rodents $(12,74,82-85)$. The route of administration, dosage, dosage regimen, and duration of dosing 
TABLE 1 | Promotion of indefinite heart or renal allograft survival in rodents by infusion of donor-derived DCreg.

\begin{tabular}{|c|c|c|c|c|c|c|c|}
\hline $\begin{array}{l}\text { DC } \\
\text { source }\end{array}$ & Species & DC culture conditions & $\begin{array}{l}\text { Route of } \\
\text { injection }\end{array}$ & $\begin{array}{l}\text { When } \\
\text { administered }^{\mathrm{a}}\end{array}$ & $\begin{array}{l}\text { Additional host } \\
\text { treatment }\end{array}$ & MST & Reference \\
\hline MoDC & rat & GM-CSF & i.v. & Day $+14 / 15$ & None & >160 days & Hayamizu et al. (86) \\
\hline BMDC & mouse & $\mathrm{GM}-\mathrm{CSF}+\mathrm{TGF} \beta$ & i.v. & Day-7 & Anti-CD40L mAb & $>100$ days $(40 \%)$ & Lu et al. (73) \\
\hline BMDC & mouse & Low GM-CSF & i.v. & Day-7 & None & $>100$ days & Lutz et al. (12) \\
\hline BMDC & mouse & $\begin{array}{l}\text { GM-CSF + IL-4 + NF-кB } \\
\text { ODN + Ad CTLA4lg }\end{array}$ & i.v. & Day-7 & None & >100 days $(40 \%)$ & Bonham et al. (74) \\
\hline BMDC & rat & $\mathrm{GM}-\mathrm{CSF}+\mathrm{IL}-4$ & i.v. & Day-7 & ALS & >200 days $(50 \%)$ & DePaz et al. (85) \\
\hline BMDC & mouse & Low GM-CSF & i.v. & Day-7 & $\begin{array}{l}\text { Anti-CD54 } \\
\text { mAb + CTLA4lg }\end{array}$ & $>100$ days & Wang et al. (83) \\
\hline BMDC & Rat $^{b}$ & GM-CSF + IL-4 + dexamethasone & i.v. & Day-10 & CTLA4lg + cyclosporine & $>100$ days & Mirenda et al. (84) \\
\hline
\end{tabular}

aln relation to transplantation on $d 0$.

${ }^{b}$ Renal transplant.

Ad, adenoviral vector; ALS, anti-lymphocyte serum; BMDC, bone marrow-derived dendritic cells; i.v., intravenous; MoDC, monocyte-derived DC; MST, mean graft survival time;

ODN, oligodeoxynucleotides decoys.

TABLE 2 | Evidence that use of standard-of-care immunosuppressive agents (corticosteroid, MMF, and CNI) together with DCreg promote long-term allograft survival in rodents.

\begin{tabular}{lll}
\hline Agent & $\begin{array}{l}\text { Type of allograft } \\
\text { (species) }\end{array}$ & Reference \\
\hline MMF & Pancreatic islet (mouse) & Adorini et al. (87) \\
Dexamathasone & Renal (rat) & Mirenda et al. (84) \\
Tacrolimus & Composite tissue (rat) & Eun et al. (88) \\
Cyclosporine & Composite tissue (rat) & Ikeguchi et al. (46) \\
& Renal (rat) & Mirenda et al. 2004 (84) \\
\hline
\end{tabular}

MMF, mycophenolate mofetil; CNI, calcineurin inhibitor.

(single i.v. infusion of up to $5 \times 10^{6}$ per kg of donor DCreg, 7 days prior to transplantation) that we propose in a phase I clinical trial are, therefore, supported by experiments in rodents [Table 1 and $(12,73,74,82-86)]$ and NHP (25). It is also important to note that use of conventional "standard of care" (SOC) immunosuppressive agents (MPA, CNI, or steroids), together with DCreg, promotes long-term allograft survival in rodents [Table 2 and (46, 84, 87, 88)]. This is of direct relevance to the use of SOC immunosuppressive therapy in our proposed clinical trial.

\section{NHP Observations}

Non-human primate transplant models are considered important predictors of the safety and efficacy of experimental immunosuppressive/tolerogenic regimens since the NHP immune system more closely resembles that of humans than mice, and since, as in humans (but not in mice), Tmem present an important and difficult to overcome barrier to induction of donor-specific tolerance (41, 89-91). We have used a robust, MHC-mismatched, lifesustaining rhesus macaque renal transplant model to evaluate the safety and efficacy of donor-derived DCreg therapy (25). In these studies, DCreg were generated from CD14 immunobead-isolated blood monocytes in a single leukapheresis product of the prospective kidney donor in granulocyte macrophage-colony-stimulating factor (GM-CSF) and IL-4. During the 7-day culture period, vitamin D3 (VitD3), a nuclear factor $\kappa \beta$ inhibitor that impairs DC differentiation and maturation $(92,93)$ and IL-10, that converts immature DC into tolerogenic APC (94), were added to promote the maturation-resistant DCreg phenotype (95). We tested whether DCreg of donor origin, infused prospectively (once only) 7 days before transplant, could safely prolong graft survival using a minimal immunosuppressive regimen of co-stimulation blockade [CTLA4Ig = cytotoxic T lymphocyte Ag 4:Ig (abatacept)] and mechanistic target of rapamycin (mTOR) inhibition [rapamycin (sirolimus)]. Our findings (25) clearly show that (1) no adverse effects were encountered, (2) no evidence of host sensitization was detected, as determined by circulating anti-donor alloAb levels, (3) graft survival time was prolonged significantly (threefold increase) in the group given DCreg compared to those recipients that did not receive the cell infusion, (4) weight loss and proteinuria were less marked in DCreg-infused monkeys, and (5) evidence was obtained of significant, donor-specific attenuation (exhaustion) of Tmem responses as evidenced by upregulation of concomitant programed death (PD)-1 and CTLA4 expression (Figure 1), reduced memory:regulatory $\mathrm{T}$ cell ratios in peripheral blood, and reduced $\mathrm{CD}^{+}$effector $\mathrm{T}$ cell responses in the transplant $(25,26)$.

\section{Human Observations}

Several pharmacologic agents and cytokines have been used to generate GMP grade autologous human DCreg for prospective clinical use in chronic inflammatory diseases, including type-1 diabetes, RA, and multiple sclerosis (48-50, 66-68). The safety of locally administered, autologous, monocyte-derived DCreg in type-1 diabetes or RA patients has been reported (48-50). To our knowledge, there has been no human experience with donor-derived DCreg in human organ transplantation. However, clinical experience with a closely related, donor-derived myeloid lineage cell product in either deceased- or live-donor renal transplantation is relevant to the proposed investigation of DCreg in organ transplantation. Thus, "immunoregulatory macrophages" (Mreg) or "transplant acceptance-inducing cells" have been investigated by Hutchinson and colleagues in Germany as immune-conditioning therapy in human renal transplantation (96). The phenotype of these cells identifies them as a subtype of partially mature macrophages (96). Initially, they were generated from deceased-donor splenic mononuclear cells cultured in macrophage (M)-CSF and IFN $\gamma$ for 5 days and administered i.v. on post-transplant day 5 . All patients $(n=12$; with $3-5$ total 


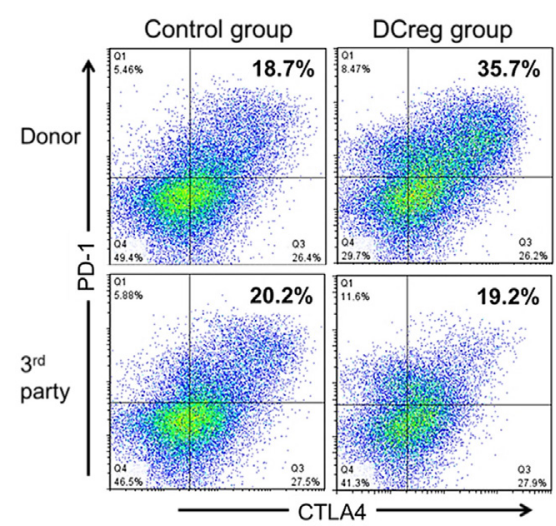

FIGURE 1 | DCreg infusion enhances programed death (PD)-1 and cytotoxic T lymphocyte antigen-4 (CTLA4) expression by donorreactive $\mathrm{CD}^{+}{ }^{+} \mathrm{Tmem}$ in renal allograft recipient monkeys. Incidences of PD1+ CTLA4+ populations in ex vivo-stimulated CD95+CD4+Tmem from representative control and DCreg-treated monkeys ( $n=4$ monkeys analyzed/ group). Recipient PBMC obtained 28 days after transplantation, were co-cultured with either donor or third party stimulators ( $T$ cell-depleted PBMC) for 5 days before flow cytometric analysis. The enhanced incidence of PD1+CTLA4 ${ }^{+}$Tmem in response to donor, but not third party stimulation suggests selective attenuation (exhaustion) of donor-reactive Tmem. According to Ezzelarab et al. (25), Figure 5.

MHC-mis-matches) received $\geq 0.55 \times 10^{6}$ viable $\mathrm{Mreg} / \mathrm{kg}$ (range $0.55-7.52 \times 10^{6} / \mathrm{kg}$ ) and were immunosuppressed at the outset with tacrolimus, sirolimus, and glucocorticoids. They were then weaned from steroid therapy, if clinically appropriate, on day 28 post-transplant. Administration of comparatively large numbers of these cells (up to $5 \times 10^{8}$ viable cells) via a central line was safe, with no evidence of graft-versus-host reactions induced by the Mreg or contaminating lymphocyte populations. Furthermore, as in our NHP DCreg studies, there was no evidence that human Mreg sensitized the recipients to donor Ags, or that the cells themselves could otherwise accelerate rejection. Importantly, none of the study participants experienced any delayed complications from Mreg infusion (mean follow-up time 36 months). Thus, it was concluded that the infusion of (donor-derived) Mreg was practicable and safe in the acute and medium term.

The same group of investigators have also infused donorderived Mreg to live-donor kidney transplant recipients $(n=5)$, 5 days before renal transplantation (97). A larger number of Mreg and a different immunosuppressive regimen [anti-thymocyte globulin (ATG), tacrolimus, and steroids] were employed. PBMC were isolated from donor leukapheresis products 14 days before transplant. On day 9 pre-transplant, non-adherent PBMC from leukapheresis products of the prospective graft recipients were added $\left(2.10^{7} / \mathrm{ml}\right)$ to the donor-derived Mreg and the co-cultures of donor origin Mreg and recipient PBMC maintained for a further 4 days until infused $\left(1.74-10.39 \times 10^{7} \mathrm{Mreg} / \mathrm{kg}\right) 5$ days before transplant. No complications were observed. Moreover, there was no evidence that infusion of donor-derived Mreg prior to transplantation could sensitize recipients to donor Ags or otherwise accelerate graft rejection. As in the earlier study, it was concluded that preoperative treatment of live-donor kidney transplant recipients with Mreg was clinically practicable and safe in the acute and medium term.

In a further (2011) publication (98), the same group (plus additional authors) reported on two live-donor renal transplant patients who were given donor-derived Mreg (99) cultured for 6 days with M-CSF before stimulation with IFN $\gamma$ for a further $24 \mathrm{~h}$, and then administered 6 or 7 days before transplant. In this case, the Mreg were CD14 ${ }^{-/ l o}, \mathrm{HLA}_{-} \mathrm{DR}{ }^{+}, \mathrm{CD} 30^{-/ \mathrm{lo}}, \mathrm{CD} 86^{+}$, $\mathrm{CD}_{16}{ }^{-}$, toll-like receptor (TLR) $2^{-}$, and $\mathrm{CD} 163^{-/ \mathrm{lo}}$. One patient (single HLA-B and HLA-DR mismatches) received $8.0 \times 10^{6}$ cells $/ \mathrm{kg}$ and the other (fully HLA-mismatched) received $7.1 \times 10^{6}$ cells $/ \mathrm{kg}$. Labeling of a proportion of the infused Mreg with $\left[{ }^{111} \mathrm{In}\right]$-oxine in one patient and whole-body single photon emission computed tomography imaging (SPECT) revealed that the Mreg located initially in the lungs, but after $2.5 \mathrm{~h}$ were evident in the circulation and had begun to accumulate in the liver and spleen. Twenty-four hours after Mreg infusion, signal from the lung had diminished substantially and the cells had accumulated in the liver, spleen, and bone marrow. Absence of signal from the patient's urinary tract throughout the $30 \mathrm{~h}$ follow-up suggested that the majority of labeled infused cells remained alive. No unexpected adverse events were observed in either patient. At 3 and 2 year, respectively, post-transplant, the patients were taking once-daily or twice-weekly tacrolimus. Despite early minimization of immunosuppressive therapy, neither patient underwent an acute rejection episode during the 3-year follow-up period.

\section{POTENTIAL MECHANISMS OF THE LONG-TERM MAINTENANCE OF SUPPRESSION AFTER DCreg ADMINISTRATION}

The in vivo mechanisms whereby infusion of donor (or recipient)derived DCreg restrains alloimmunity and promotes long-term survival of experimental organ allografts are not well understood. In mice, there is evidence that donor-derived DCreg infused before transplantation are targeted by host NK cells and, thus, short-lived (35). They are reprocessed by quiescent host splenic DCs for presentation of alloAg to indirect pathway $\mathrm{CD}^{+} \mathrm{T}$ cells. This results in abortive activation and deletion of $\mathrm{T}$ effector cells without impairing the incidence of indirect $\mathrm{CD} 4^{+}$Foxp $3^{+}$Treg, thus enhancing the regulatory to effector $\mathrm{T}$ cell ratio $(33,100)$. It appears, therefore, that mechanisms that sustain long-term graft survival are not dependent on persistence of intact donor DCreg.

\section{PROPOSED CLINICAL TESTING OF DCreg IN RENAL TRANSPLANTATION}

Here, we propose a protocol for the generation and testing of donor-derived DCreg in a phase I clinical trial in renal transplant recipients receiving conventional immunosuppressive therapy.

\section{Generation, Purity, and Yield of hu DCreg}

To ensure sufficient DCreg yields, blood monocytes will be obtained and banked in high purity by elutriation from 
cryopreserved leukapheresis products of the prospective transplant donors approximately 28-15 days before scheduled transplantation (Figure 2). Fourteen days before transplantation, monocytes will be thawed and DCreg generated for infusion into the prospective graft recipient on day-7 (Figure 1). In our experience, whole individual leukapheresis products from nonmobilized, healthy adult volunteers yield $4.3 \pm 1.05 \times 10^{9} \mathrm{PBMC}$. Recovery of monocytes post-elutriation [consistently $\geq 90 \%$ pure with $<1 \% \mathrm{CD}^{+} \mathrm{T}$ cell contamination $(n=4)$ ] represents, on average, $25 \%$ of the total PBMC. The phenotype of the purified monocytes, determined by flow cytometry, is HLA-DR ${ }^{+} \mathrm{CD} 40^{\text {lo }}$ $\mathrm{CD} 0^{\mathrm{lo}} \mathrm{CD} 6^{+}$, programed death ligand (PD-L) $1^{\text {lo }}, \mathrm{CD} 14^{+}$.

The DCreg are generated from thawed monocytes in serumfree Cell Genix (Cellgro) medium, supplemented with 5\% certified human $\mathrm{AB}$ serum and recombinant human (rhu) GM-CSF (1000 units/ml) and rhu IL-4. These cytokines are added at the start of culture (day 0) and on day 4 . VitD3 and rhu IL-10, which suppress DC maturation $(94,101,102)$, are also added on day 4. The culture period is 7 days. We consistently generate sufficient, highly purified DCreg from elutriated peripheral blood monocytes (yield $=17 \pm 7 \%$ of starting monocyte number) from a single whole leukapheresis product to administer up to $2.0-2.5 \times 10^{6}$ per $\mathrm{kg}$ to a $70 \mathrm{~kg}$ recipient. To obtain larger numbers of DCreg for a higher dose, a second donor leukapheresis may be required.

The DCreg harvested at day 7 of culture are consistently $>94 \%$ pure, with $\leq 0.1 \%$ contaminating $\mathrm{CD}^{+} \mathrm{T}$ lymphocytes determined by flow cytometry. It is especially significant that the incidence of $\mathrm{T}$ cells is so low since these are the cells that are of concern regarding risk of graft-versus-host disease. The DCreg consistently exhibit an immature phenotype compared to control DC (i.e., immature DC generated in DC media without VitD3 and IL-10) and are HLA-DR ${ }^{+}, \mathrm{CD} 11 \mathrm{c}^{+}, \mathrm{CD} 14^{-}, \mathrm{CD} 40^{\mathrm{lo}}$, $\mathrm{CD}^{2} 0^{\text {lo }}, \mathrm{CD} 6^{\text {lo }}, \mathrm{PD}-\mathrm{L1}^{\text {hi }}, \mathrm{CCR}^{+}, \mathrm{CD}^{2} 3^{\text {lo }}$. High expression of $\mathrm{PD}-\mathrm{L} 1(=\mathrm{B} 7-\mathrm{H} 1)$, a negative regulator of $\mathrm{T}$ cell responses and

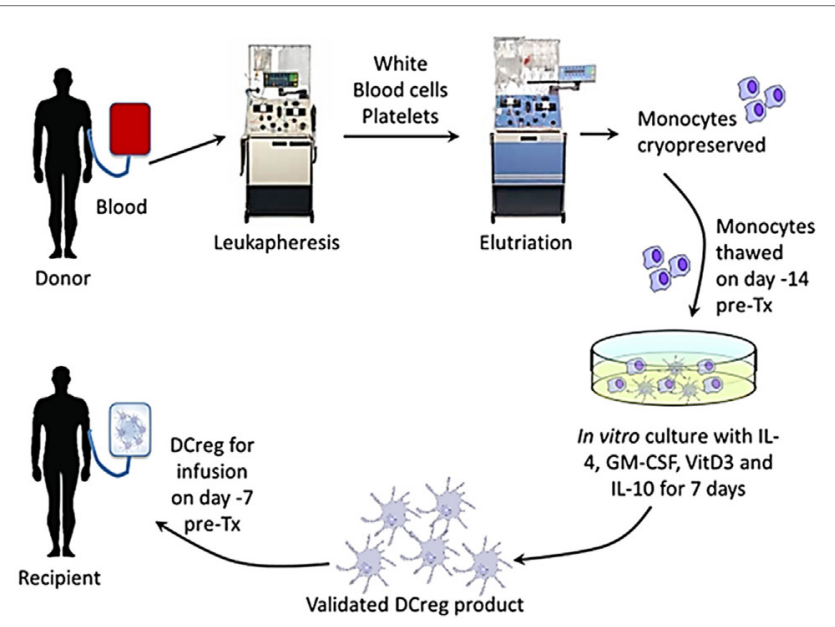

FIGURE 2 | Generation of DCreg from elutriated blood monocytes of the prospective renal allograft donor in GM-CSF, VitD3, and IL-10, and infusion of the validated cell product into the graft recipient 7 days before transplant. a consistently high $\mathrm{PD}-\mathrm{L} 1: \mathrm{CD} 86$ ratio [determined as: $\mathrm{PD}-\mathrm{L} 1$ mean fluorescence intensity (MFI) $\div$ isotype control/CD86 (MFI) $\div$ isotype control] conforms to that of DCreg with potential to subvert alloreactive $\mathrm{T}$ cell responses.

\section{Function of DCreg}

Investigation of the function of hu DCreg harvested at 7 days of culture, including their responses to the TLR4 ligand bacterial lipopolysaccharide (LPS), CD40 ligation, or a pro-inflammatory cytokine cocktail, will ensure their regulatory properties. The DCreg we have generated display robust resistance to phenotypic and functional maturation in response to factors that promote the maturation of control DC, confirming that they are refractory to stimulation under inflammatory conditions. In particular, the inability of DCreg exposed to LPS to release pro-inflammatory and immunostimulatory cytokines (tumor necrosis factor $[\mathrm{TNF}] \alpha$ and IL-12p70) is profoundly inhibited, while production of anti-inflammatory IL-10 is preserved, resulting in marked reversal of the IL-12:IL-10 and TNF $:$ :IL-10 ratios.

The ability of the DCreg exposed to LPS to induce hyporesponsiveness of normal allogeneic T cells is of paramount importance. Therefore, DCreg (ratio 1 DCreg:40 T cells) should induce minimal CD4 and CD8 T cell proliferation, IFN $\gamma$ and IL-17 release, or granzyme B production in the responder $\mathrm{CD} 4^{+} \mathrm{T}$ cells over 4 days in culture. This analysis provides further assurance of the inability of the DCreg, despite exposure to a potent proinflammatory stimulus (LPS), to stimulate allogeneic effector T cell responses. Similarly, marked attenuation of alloreactive CD8 ${ }^{+}$ $\mathrm{T}$ cell responses is observed.

Thus, we contend that infusion of DCreg that are (1) phenotypically immature, (2) resistant to maturation under inflammatory conditions, and (3) able to induce allogeneic $\mathrm{T}$ cell hyporesponsiveness in vitro will not induce sensitization of prospective recipients following their adoptive in vivo cell transfer and rather, will induce donor-specific T cell hyporesponsiveness. Our plan to closely monitor study patients for evidence of development of donor-specific alloAb production and anti-donor $\mathrm{T}$ cell reactivity will allow detection of any increase in anti-donor immune effector activity in the unlikely event it should occur.

\section{Release Criteria for DCreg}

The DCreg generated for infusion will undergo rigorous testing at specified time points during their manufacture from blood monocytes. The following release criteria will be considered as crucially important: DCreg yield (sufficient cells to allow infusion of the target number per kilogram), percent purity (>95\% DC, $<1 \%$ T cells), and viability (>70\%); sterility; DCreg phenotype: phenotypic characterization will be performed by flow cytometry to monitor CD86 and PD-L1 expression before and after LPS stimulation, compared to conventional DC cultured in GM-CSF + IL-4 and not VitD3 and IL-10. High PD-L1 and low CD86 expression, before and after LPS stimulation, with a PD-L1:CD86 ratio $>3.5$ (based on pre-clinical results) will be used as a release criterion. The 3.5 ratio is based on many analyses in which a ratio of 3.5 or above was associated with a cytokine profile and T cell stimulatory profile consistent with the induction of alloreactive T cell hyporesponsiveness. DCreg function: 
supernatants from cultures (DCreg exposed or not to LPS) will be tested by ELISA to assess the lack of IL-12p70/TNF- $\alpha$ and the presence of IL-10 production, consistent with their regulatory properties and their resistance to maturation. We consider this, in addition to the tests above, a simple, reproducible, release criterion that can be applied before release of the DCreg product for infusion.

\section{DCreg Infusion}

We plan to test three dose levels of DCreg in three separate groups of recipients ( $n=5$ /group, with 4 receiving DCreg and 1 "control" subject receiving concomitant pre- and post-transplant immunosuppression without DCreg): dose 1: $0.5 \times 10^{6}$ cells $/ \mathrm{kg}$ body weight; dose 2: $2.5 \times 10^{6}$ cells $/ \mathrm{kg}$ body weight; dose $3: 5 \times 10^{6}$ cells/kg body weight.

\section{Concurrent Immunosuppressive Drug Regimen}

The renal transplant recipients will receive combination immunosuppressive medications according to SOC at our Institute, with two exceptions. First, MPA (that blocks DNA synthesis in T and B cells) will be initiated 7 days before transplant, at the time of donor DCreg infusion, instead of on the day of transplantation. This is in order to minimize any risk of sensitizing the patient. Historically, pre-treatment of kidney transplant recipients with unmodified donor-specific transfusions and low-dose azathioprine (that acts similarly to MPA) significantly reduced the risk of sensitization (103-107). Furthermore, MPA augments and maintains the regulatory function of DC $(108,109)$, additionally minimizing any safety concern that DCreg could convert to a stimulatory phenotype after infusion. Second, Ab induction therapy will not be administered at the time of transplant. Patients will be maintained on triple immunosuppressive therapy with MPA, tacrolimus, and prednisone after transplantation, a combination regimen widely applied as SOC at many transplant centers, both in North America and elsewhere worldwide and in The ONE Study of regulatory immune cell therapy in renal transplantation ${ }^{2}$, a trans-Atlantic (European and North American) trial utilizing a unified approach to evaluating immune cell therapy in renal transplantation for the reasons outlined above. The immunosuppressive drug regimen that we propose differs from the regimen (belatacept and rapamycin) that we used together with DCreg in NHP (25). This is because belatacept plus rapamycin is not SOC in human renal transplantation and it is important to assess the safety and efficacy of DCreg in humans in comparison with current SOC, as being evaluated in The ONE study, including the testing of autologous DCreg.

The rationale for not using ATG, alemtuzumab (anti-CD52 $\mathrm{mAb}$ ) or basiliximab (anti-IL-2R $\alpha \mathrm{mAb}$ ) as induction therapy at transplant, is to avoid potential targeting of DCreg infused 7 days before transplant or dampening of immunoregulatory pathways triggered in host T cells by DCreg. In our NHP study, we established that such an approach (pre-transplant immunosuppression at the time of DCreg infusion and avoidance of

${ }^{2}$ http://www.onestudy.org lymphocyte-depleting induction agents) is both safe and effective. We have opted, however, not to use a Co-B and/or mTOR inhibition-based immunosuppressive regimen, such as that employed in our NHP study, because of the high incidence of acute rejection episodes, including higher grade rejection, in patients receiving Co-B (belatacept), MPA, and steroid therapy and increased side effects in clinical trials of rapamycin-based regimens, either with CNI or MPA $(3,5)$. Since our initial proposed clinical trial is a safety trial, we have chosen to adhere to a safe and proven immunosuppression regimen that does not interfere with DCreg action.

\section{Persistence of Donor DCreg after Infusion}

Monitoring DCreg persistence in the circulation and their tissue homing is essential for understanding their survival and distribution. Flow cytometry techniques to detect donor T cells in peripheral blood of transplant recipients with a threshold sensitivity of one donor cell in 1000 recipient cells $(0.1 \%)$ are readily available (110). We plan to identify donor DCreg in whole blood at various time points post-transplant, by flow staining for $\mathrm{Lin}^{-}$, $\mathrm{HLA}_{-D R}^{+}, \mathrm{BDCA} 1(\mathrm{CD} 1 \mathrm{c})^{+}, \mathrm{CD} 209$ (DC SIGN) ${ }^{+}, \mathrm{CD} 11 \mathrm{c}^{+}$DC, in conjunction with staining for a miss-matched donor $\mathrm{MHC}$ allele. This approach will allow us distinguish between recipient and donor-derived DCreg. Others (98) have used [ $\left.{ }^{111} \mathrm{In}\right]$-oxine to label allogeneic donor-derived myeloid cells (Mreg) for short-term tracking by SPECT imaging following their infusion in renal transplant patients and we will consider using this as a complementary approach.

\section{Mechanistic and Immunological Monitoring Analyses of Transplant Recipients}

Cellular pathways engaged after organ transplantation are complex and involve coordinated interactions between DC as APC and distinct effector and regulatory $\mathrm{T}$ cell subsets, which can lead to a state of Ag-cognate effector cell hyporesponsiveness (graft acceptance or quiescence). While it is believed that DCreg are effective in blunting Tmem responses $(25,38-40)$ and de novoprimed naive $\mathrm{T}$ cells $(13,34)$, it is unclear how long after infusion donor-derived DCreg persist in the peripheral blood or in lymphoid tissue of transplant patients, and which mechanism(s) (clonal deletion, anergy, regulation, or exhaustion) may contribute to inducing donor-specific $\mathrm{T}$ cell hyporesponsiveness. Our hypothesis is that infusion of donor-derived DCreg (even if their survival is short-lived) (35) will induce donor-specific $\mathrm{T}$ cell hyporesponsiveness in the recipient, while nominal $\mathrm{T}$ cell recall responses [such as those to anti-Epstein-Barr virus (EBV) or tetanus toxoid (TT)] will be preserved. This could be mediated by decreased donor allo-specific Tmem frequencies and result in residual low allo-specific Tmem proliferation, IFN- $\gamma$ and Granzyme B/Perforin production in response to donor Ag stimulation, but with preserved responses to EBV and TT stimulation.

To address these questions, we will collect blood samples pre-transplant on day -7 (pre DCreg infusion), on day 0 , and at 3 months, 1 year, and 2 year post-transplant. We will (1) characterize the phenotype, memory differentiation, and function of 
different T cell subsets, (2) assess donor-reactive T cell clonality and function, (3) identify effector and regulatory cells and molecules in for-cause and protocol biopsy samples. While no single immunologic test can identify peripheral hyporesponsiveness after organ transplantation, we will attempt to assess multiple essential $\mathrm{T}$ cell immune parameters methodically at the same time, an approach expected to provide a possible signature and mechanism of peripheral anti-donor hyporesponsiveness after DCreg infusion.

We will assess $\mathrm{T}$ cell expression of co-stimulatory receptors [e.g., CD28, inducible costimulator (ICOS) and CD40L], which are critical for cross-talk with DC, as well as co-inhibitory receptors [PD-1, TIM3 (T cell immunoglobulin mucin domain 3) and cytotoxic T lymphocyte Ag (CTLA)-4] that are up-regulated on recently activated/exhausted $\mathrm{T}$ cells in conjunction with expression of Annexin V/7-AAD to track apoptosis. We will also track EBV-specific and anti-TT T cells as controls for recall responses. We will correlate the levels of memory $\mathrm{CD} 8^{+}, \mathrm{CD} 4^{+} \mathrm{T}_{\mathrm{FH}}$, and $\mathrm{CD}^{+}$Tconv effectors with Treg, DSA titer, plasma cytokines and effector and regulatory cell, IgG, and complement (C4d) deposition in the allograft. Age-matched healthy controls and renal transplant patients who did not receive DCreg infusion will serve as controls.

\section{CONCLUSION}

There is extensive evidence that DCreg of donor origin can regulate alloimmune responses and promote long-term organ transplant survival in rodents. The recent observation that DCreg can safely prolong renal transplant survival in a robust, pre-clinical NHP model, in which the graft recipients received a

\section{REFERENCES}

1. Meier-Kriesche HU, Schold JD, Kaplan B. Long-term renal allograft survival: have we made significant progress or is it time to rethink our analytic and therapeutic strategies? Am J Transplant (2004) 4:1289-95. doi:10.1111/j.1600-6143.2004.00515.x

2. Lamb KE, Lodhi S, Meier-Kriesche HU. Long-term renal allograft survival in the United States: a critical reappraisal. Am J Transplant (2011) 11:450-62. doi:10.1111/j.1600-6143.2010.03283.x

3. Vincenti F, Charpentier B, Vanrenterghem Y, Rostaing L, Bresnahan B, Darji P, et al. A phase III study of belatacept-based immunosuppression regimens versus cyclosporine in renal transplant recipients (BENEFIT study). Am J Transplant (2010) 10:535-46. doi:10.1111/j.1600-6143.2009.03005.x

4. Hricik DE, Formica RN, Nickerson P, Rush D, Fairchild RL, Poggio ED, et al. Adverse outcomes of tacrolimus withdrawal in immune-quiescent kidney transplant recipients. J Am Soc Nephrol (2015) 26:3114-22. doi:10.1681/ ASN.2014121234

5. Ekberg H, Tedesco-Silva H, Demirbas A, Vitko S, Nashan B, Gurkan A, et al. Reduced exposure to calcineurin inhibitors in renal transplantation. $\mathrm{N} \mathrm{Engl} \mathrm{J}$ Med (2007) 357:2562-75. doi:10.1056/NEJMoa067411

6. Billingham RE, Brent L, Medawar PB. Actively acquired tolerance of foreign cells. Nature (1953) 172:603-6. doi:10.1038/172603a0

7. Kawai T, Leventhal J, Madsen JC, Strober S, Turka LA, Wood KJ. Tolerance: one transplant for life. Transplantation (2014) 98:117-21. doi:10.1097/ TP.0000000000000260

8. Ohnmacht C, Pullner A, King SB, Drexler I, Meier S, Brocker T, et al. Constitutive ablation of dendritic cells breaks self-tolerance of CD4 T cells minimal immunosuppressive regimen, provides further justification for a clinical trial. Appropriate culture conditions, leading to the manufacture of GMP grade DCreg, which are resistant to maturation and have potential to regulate host alloimmunity, have been developed for clinical testing.

\section{AUTHOR CONTRIBUTIONS}

AT, AZ, ME, LB, FL, and DM each contributed to the conception and writing of the work, revised it critically, finally approved the submitted version of the manuscript, and agreed to be accountable for all aspects of the accuracy and integrity of the work.

\section{ACKNOWLEDGMENTS}

The work was supported by National Institutes of Health (NIH) grants 5 UL1 TR0000005-09 (AT) and R21 AI116746 (DM) and by the UPCI Immunologic Monitoring and Cellular Products Laboratory that is supported, in part, by NIH award P30CA047904. We thank our colleagues, Drs. Sundaram Hariharan, Paul Szabolcs, Amit Tevar, and Mindi Styn for their contributions to the conception and design of the work. We thank Dr. Dalia Raich-Regue for her input in formatting of Figure 2.

\section{FUNDING}

The work was supported by National Institutes of Health (NIH) grants 5 UL1 TR0000005-09 (AWT) and R21 AI116746 (DM) and by the UPCI Immunologic Monitoring and Cellular Products Laboratory that is supported, in part, by NIH award P30CA047904.

and results in spontaneous fatal autoimmunity. J Exp Med (2009) 206:549-59. doi:10.1084/jem.20082394

9. Sakaguchi S. Naturally arising CD4+ regulatory T cells for immunologic self-tolerance and negative control of immune responses. Annu Rev Immunol (2004) 22:531-62. doi:10.1146/annurev.immunol.21.120601.141122

10. Beriou G, Peche H, Guillonneau C, Merieau E, Cuturi MC. Donor-specific allograft tolerance by administration of recipient-derived immature dendritic cells and suboptimal immunosuppression. Transplantation (2005) 79:969-72. doi:10.1097/01.TP.0000158277.50073.35

11. Hill M, Thebault P, Segovia M, Louvet C, Beriou G, Tilly G, et al. Cell therapy with autologous tolerogenic dendritic cells induces allograft tolerance through interferon-gamma and epstein-barr virus-induced gene 3. Am J Transplant (2011) 11:2036-45. doi:10.1111/j.1600-6143.2011.03651.x

12. Lutz MB, Suri RM, Niimi M, Ogilvie AL, Kukutsch NA, Rossner $S$, et al. Immature dendritic cells generated with low doses of GM-CSF in the absence of IL-4 are maturation resistant and prolong allograft survival in vivo. Eur J Immunol (2000) 30:1813-22. doi:10.1002/1521-4141(200007)30:7<1813::AID-IMMU1813>3.0.CO;2-8

13. Morelli AE, Thomson AW. Tolerogenic dendritic cells and the quest for transplant tolerance. Nat Rev Immunol (2007) 7:610-21. doi:10.1038/nri2132

14. Kingsley C, Karim M, Bushell A, Wood K. CD25+CD4+ regulatory T cells prevent graft rejection:CTLA-4- and IL-10-dependent immunoregulation of alloresponses. J Immunol (2002) 168:1080-6. doi:10.4049/ jimmunol.168.3.1080

15. Wood KJ, Bushell A, Hester J. Regulatory immune cells in transplantation. Nat Rev Immunol (2012) 12:417-30. doi:10.1038/nri3227

16. Brem-Exner BG, Sattler C, Hutchinson JA, Koehl GE, Kronenberg K, Farkas S, et al. Macrophages driven to a novel state of activation have 
anti-inflammatory properties in mice. J Immunol (2008) 180:335-49. doi:10.4049/jimmunol.180.1.335

17. Fleming $\mathrm{BD}$, Mosser DM. Regulatory macrophages: setting the threshold for therapy. Eur J Immunol (2011) 41:2498-502. doi:10.1002/ eji.201141717

18. Broichhausen C, Riquelme P, Geissler EK, Hutchinson JA. Regulatory macrophages as therapeutic targets and therapeutic agents in solid organ transplantation. Curr Opin Organ Transplant (2012) 17:332-42. doi:10.1097/ MOT.0b013e328355a979

19. Ochando J, Conde P, Bronte V. Monocyte-derived suppressor cells in transplantation. Curr Transplant Rep (2015) 2:176-83. doi:10.1007/ s40472-015-0054-9

20. Roncarolo MG, Gregori S, Bacchetta R, Battaglia M. Tr1 cells and the counter-regulation of immunity: natural mechanisms and therapeutic applications. Curr Top Microbiol Immunol (2014) 380:39-68. doi:10.1007/978-3-662-43492-5_3

21. Sicard A, Koenig A, Morelon E, Defrance T, Thaunat O. Cell therapy to induce allograft tolerance: time to switch to plan B? Front Immunol (2015) 6:149. doi:10.3389/fimmu.2015.00149

22. Ezzelarab M, Thomson AW. Tolerogenic dendritic cells and their role in transplantation. Semin Immunol (2011) 23:252-63. doi:10.1016/j. smim.2011.06.007

23. Beriou G, Moreau A, Cuturi MC. Tolerogenic dendritic cells: applications for solid organ transplantation. Curr Opin Organ Transplant (2012) 17:42-7. doi:10.1097/MOT.0b013e32834ee662

24. Vassalli G. Dendritic cell-based approaches for therapeutic immune regulation in solid-organ transplantation. J Transplant (2013) 2013:761429. doi:10.1155/2013/761429

25. Ezzelarab MB, Zahorchak AF, Lu L, Morelli AE, Chalasani G, Demetris AJ, et al. Regulatory dendritic cell infusion prolongs kidney allograft survival in nonhuman primates. Am J Transplant (2013) 13:1989-2005. doi:10.1111/ ajt.12310

26. Ezzelarab MB, Lu L, Guo H, Zahorchak AF, Shufesky WJ, Cooper DK, et al. Eomesodermin ${ }^{\text {lo }} \mathrm{CTLA}^{\text {hi }}$ alloreactive $\mathrm{CD} 8^{+}$memory T cells are associated with prolonged renal transplant survival induced by regulatory dendritic cell infusion in CTLA4Ig-treated non-human primates. Transplantation (2016) 100:91-102.

27. Lakkis FG, Sayegh MH. Memory T cells: a hurdle to immunologic tolerance. J Am Soc Nephrol (2003) 14:2402-10. doi:10.1097/01. ASN.0000085020.78117.70

28. Valujskikh A. The challenge of inhibiting alloreactive T-cell memory. Am J Transplant (2006) 6:647-51. doi:10.1111/j.1600-6143.2005.01215.x

29. Moreau A, Varey E, Bouchet-Delbos L, Cuturi MC. Cell therapy using tolerogenic dendritic cells in transplantation. Transplant Res (2012) 1:13. doi:10.1186/2047-1440-1-13

30. Geissler EK, The ONE. Study compares cell therapy products in organ transplantation: introduction to a review series on suppressive monocyte-derived cells. Transplant Res (2012) 1:11. doi:10.1186/2047-1440-1-10

31. Banchereau J, Steinman RM. Dendritic cells and the control of immunity. Nature (1998) 392:245-52. doi:10.1038/32588

32. Steinman RM, Hawiger D, Nussenzweig MC. Tolerogenic dendritic cells. Annu Rev Immunol (2003) 21:685-711. doi:10.1146/annurev. immunol.21.120601.141040

33. Wang Z, Divito SJ, Shufesky WJ, Sumpter T, Wang H, Tkacheva OA, et al. Dendritic cell therapies in transplantation revisited: deletion of recipient DCs deters the effect of therapeutic DCs. Am J Transplant (2012) 12:1398-408. doi:10.1111/j.1600-6143.2012.04060.x

34. Morelli AE, Thomson AW. Orchestration of transplantation tolerance by regulatory dendritic cell therapy or in-situ targeting of dendritic cells. Curr Opin Organ Transplant (2014) 19:348-56. doi:10.1097/ MOT.0000000000000097

35. Divito SJ, Wang Z, Shufesky WJ, Liu Q, Tkacheva OA, Montecalvo A, et al. Endogenous dendritic cells mediate the effects of intravenously injected therapeutic immunosuppressive dendritic cells in transplantation. Blood (2010) 116:2694-705. doi:10.1182/blood-2009-10-251058

36. Riley JL, June CH, Blazar BR. Human T regulatory cell therapy: take a billion or so and call me in the morning. Immunity (2009) 30:656-65. doi:10.1016/j. immuni.2009.04.006
37. Tang Q, Lee K. Regulatory T-cell therapy for transplantation: how many cells do we need? Curr Opin Organ Transplant (2012) 17:349-54. doi:10.1097/ MOT.0b013e328355a992

38. Nasreen M, Waldie TM, Dixon CM, Steptoe RJ. Steady-state antigen-expressing dendritic cells terminate CD4+ memory T-cell responses. Eur J Immunol (2010) 40:2016-25. doi:10.1002/eji.200940085

39. Anderson AE, Sayers BL, Haniffa MA, Swan DJ, Diboll J, Wang XN, et al. Differential regulation of naive and memory $\mathrm{CD} 4+\mathrm{T}$ cells by alternatively activated dendritic cells. J Leukoc Biol (2008) 84:124-33. doi:10.1189/ jlb.1107744

40. Kenna TJ, Waldie T, McNally A, Thomson M, Yagita H, Thomas R, et al. Targeting antigen to diverse APCs inactivates memory CD8+ T cells without eliciting tissue-destructive effector function. J Immunol (2010) 184:598-606. doi:10.4049/jimmunol.0900032

41. Macedo C, Orkis EA, Popescu I, Elinoff BD, Zeevi A, Shapiro R, et al. Contribution of naive and memory T-cell populations to the human alloimmune response. Am J Transplant (2009) 9:2057-66. doi:10.1111/j.1600-6143.2009.02742.x

42. Ford ML, Kirk AD, Larsen CP. Donor-reactive T-cell stimulation history and precursor frequency: barriers to tolerance induction. Transplantation (2009) 87:S69-74. doi:10.1097/TP.0b013e3181a2a701

43. Ford ML, Larsen CP. Overcoming the memory barrier in tolerance induction: molecular mimicry and functional heterogeneity among pathogen-specific T-cell populations. Curr Opin Organ Transplant (2010) 15:405-10. doi:10.1097/MOT.0b013e32833b7916

44. Dhodapkar MV, Steinman RM, Krasovsky J, Munz C, Bhardwaj N. Antigenspecific inhibition of effector $\mathrm{T}$ cell function in humans after injection of immature dendritic cells. J Exp Med (2001) 193:233-8. doi:10.1084/ jem.193.2.233

45. Dhodapkar MV, Steinman RM. Antigen-bearing immature dendritic cells induce peptide-specific $\mathrm{CD} 8(+)$ regulatory T cells in vivo in humans. Blood (2002) 100:174-7. doi:10.1182/blood.V100.1.174

46. Ikeguchi R, Sacks JM, Unadkat JV, Solari M, Horibe EK, Thomson AW, et al. Long-term survival of limb allografts induced by pharmacologically conditioned, donor alloantigen-pulsed dendritic cells without maintenance immunosuppression. Transplantation (2008) 85:237-46. doi:10.1097/ TP.0b013e31815e870e

47. Horibe EK, Sacks J, Unadkat J, Raimondi G, Wang Z, Ikeguchi R, et al. Rapamycin-conditioned, alloantigen-pulsed dendritic cells promote indefinite survival of vascularized skin allografts in association with $\mathrm{T}$ regulatory cell expansion. Transpl Immunol (2008) 18:307-18. doi:10.1016/j. trim.2007.10.007

48. Giannoukakis N, Phillips B, Finegold D, Harnaha J, Trucco M. Phase I (safety) study of autologous tolerogenic dendritic cells in type 1 diabetic patients. Diabetes Care (2011) 34:2026-32. doi:10.2337/dc11-0472

49. Thomas R, Street S, Ramnoruth N. Safety and preliminary evidence of efficacy in a phase I clinical trial of autologous tolerizing dendritic cells exposed to citrullinated peptides (Rheumavax) in patients with rheumatoid arthritis. Ann Rheum Dis (2011) 70:169.

50. Benham H, Nel HJ, Law SC, Mehdi AM, Street S, Ramnoruth N, et al. Citrullinated peptide dendritic cell immunotherapy in HLA risk genotype-positive rheumatoid arthritis patients. Sci Transl Med (2015) 7:290ra87. doi:10.1126/scitranslmed.aaa9301

51. Steinman RM, Cohn ZA. Identification of a novel cell type in peripheral lymphoid organs of mice. I. Morphology, quantitation, tissue distribution. J Exp Med (1973) 137:1142-62. doi:10.1084/jem.137.5.1142

52. Steinman RM. The dendritic cell system and its role in immunogenicity. Annu Rev Immunol (1991) 9:271-96. doi:10.1146/annurev. iy.09.040191.001415

53. Steptoe RJ, Thomson AW. Dendritic cells and tolerance induction. Clin Exp Immunol (1996) 105:397-402. doi:10.1046/j.1365-2249.1996.d01-779.x

54. Maldonado RA, von Andrian UH. How tolerogenic dendritic cells induce regulatory T cells. Adv Immunol (2010) 108:111-65. doi:10.1016/ B978-0-12-380995-7.00004-5

55. Steinman RM, Hawiger D, Liu K, Bonifaz L, Bonnyay D, Mahnke K, et al. Dendritic cell function in vivo during the steady state: a role in peripheral tolerance. Ann N Y Acad Sci (2003) 987:15-25. doi:10.1111/j.1749-6632.2003. tb06029.x 
56. Probst HC, Muth S, Schild H. Regulation of the tolerogenic function of steadystate DCs. Eur J Immunol (2014) 44:927-33. doi:10.1002/eji.201343862

57. Coates PT, Thomson AW. Dendritic cells, tolerance induction and transplant outcome. Am J Transplant (2002) 2:299-307. doi:10.1034/j.1600-6143.2002.20403.x

58. Thomson AW, Knolle PA. Antigen-presenting cell function in the tolerogenic liver environment. Nat Rev Immunol (2010) 10:753-66. doi:10.1038/nri2858

59. Rogers NM, Isenberg JS, Thomson AW. Plasmacytoid dendritic cells: no longer an enigma and now key to transplant tolerance? Am J Transplant (2013) 13:1125-33. doi:10.1111/ajt.12229

60. Thomson AW, Robbins PD. Tolerogenic dendritic cells for autoimmune disease and transplantation. Ann Rheum Dis (2008) 67(Suppl 3):iii90-6. doi:10.1136/ard.2008.099176

61. Hilkens CM, Isaacs JD, Thomson AW. Development of dendritic cell-based immunotherapy for autoimmunity. Int Rev Immunol (2010) 29:156-83. doi:10.3109/08830180903281193

62. Stoop JN, Robinson JH, Hilkens CM. Developing tolerogenic dendritic cell therapy for rheumatoid arthritis: what can we learn from mouse models? Ann Rheum Dis (2011) 70:1526-33. doi:10.1136/ard.2011.151654

63. Van Brussel I, Lee WP, Rombouts M, Nuyts AH, Heylen M, De Winter BY, et al. Tolerogenic dendritic cell vaccines to treat autoimmune diseases: can the unattainable dream turn into reality? Autoimmun Rev (2014) 13:138-50. doi:10.1016/j.autrev.2013.09.008

64. Eto M, Hackstein H, Kaneko K, Nomoto K, Thomson AW. Promotion of skin graft tolerance across MHC barriers by mobilization of dendritic cells in donor hemopoietic cell infusions. JImmunol (2002) 169:2390-6. doi:10.4049/jimmunol.169.5.2390

65. Zahorchak AF, Kean LS, Tokita D, Turnquist HR, Abe M, Finke J, et al. Infusion of stably immature monocyte-derived dendritic cells plus CTLA4Ig modulates alloimmune reactivity in rhesus macaques. Transplantation (2007) 84:196-206. doi:10.1097/01.tp.0000268582.21168.f6

66. Harry RA, Anderson AE, Isaacs JD, Hilkens CM. Generation and characterisation of therapeutic tolerogenic dendritic cells for rheumatoid arthritis. Ann Rheum Dis (2010) 69:2042-50. doi:10.1136/ard.2009.126383

67. Naranjo-Gomez M, Raich-Regue D, Onate C, Grau-Lopez L, Ramo-Tello C, Pujol-Borrell R, et al. Comparative study of clinical grade human tolerogenic dendritic cells. J Transl Med (2011) 9:89. doi:10.1186/1479-5876-9-89

68. Boks MA, Kager-Groenland JR, Haasjes MS, Zwaginga JJ, van Ham SM, ten Brinke A. IL-10-generated tolerogenic dendritic cells are optimal for functional regulatory $\mathrm{T}$ cell induction - a comparative study of human clinical-applicable DC. Clin Immunol (2012) 142:332-42. doi:10.1016/j. clim.2011.11.011

69. Raich-Regue D, Naranjo-Gomez M, Grau-Lopez L, Ramo C, Pujol-Borrell R, Martinez-Caceres E, et al. Differential effects of monophosphoryl lipid A and cytokine cocktail as maturation stimuli of immunogenic and tolerogenic dendritic cells for immunotherapy. Vaccine (2012) 30:378-87. doi:10.1016/j. vaccine.2011.10.081

70. Raich-Regue D, Grau-Lopez L, Naranjo-Gomez M, Ramo-Tello C, PujolBorrell R, Martinez-Caceres E, et al. Stable antigen-specific T-cell hyporesponsiveness induced by tolerogenic dendritic cells from multiple sclerosis patients. Eur J Immunol (2012) 42:771-82. doi:10.1002/eji.201141835

71. Rastellini C, Lu L, Ricordi C, Starzl TE, Rao AS, Thomson AW. Granulocyte/ macrophage colony-stimulating factor-stimulated hepatic dendritic cell progenitors prolong pancreatic islet allograft survival. Transplantation (1995) 60:1366-70

72. Fu F, Li Y, Qian S, Lu L, Chambers F, Starzl TE, et al. Costimulatory molecule-deficient dendritic cell progenitors (MHC class $\mathrm{II}^{+}$, $\mathrm{CD}^{\mathrm{dim}}{ }^{\mathrm{d}}$ CD86-) prolong cardiac allograft survival in nonimmunosuppressed recipients. Transplantation (1996) 62:659-65. doi:10.1097/00007890-199609150-00021

73. Lu L, Li W, Fu F, Chambers FG, Qian S, Fung JJ, et al. Blockade of the CD40-CD40 ligand pathway potentiates the capacity of donor-derived dendritic cell progenitors to induce long-term cardiac allograft survival. Transplantation (1997) 64:1808-15. doi:10.1097/00007890-199712270-00031

74. Bonham CA, Peng L, Liang X, Chen Z, Wang L, Ma L, et al. Marked prolongation of cardiac allograft survival by dendritic cells genetically engineered with NF-kappa B oligodeoxyribonucleotide decoys and adenoviral vectors encoding CTLA4-Ig. J Immunol (2002) 169:3382-91. doi:10.4049/ jimmunol.169.6.3382
75. Wang Z, Morelli AE, Hackstein H, Kaneko K, Thomson AW. Marked inhibition of transplant vascular sclerosis by in vivo-mobilized donor dendritic cells and anti-CD154 mAb. Transplantation (2003) 76:562-71. doi:10.1097/01. TP.0000068901.11693.C3

76. Taner T, Hackstein H, Wang Z, Morelli AE, Thomson AW. Rapamycintreated, alloantigen-pulsed host dendritic cells induce Ag-specific $\mathrm{T}$ cell regulation and prolong graft survival. Am J Transplant (2005) 5:228-36. doi:10.1046/j.1600-6143.2004.00673.x

77. Abe M, Wang Z, De Creus A, Thomson AW. Plasmacytoid dendritic cell precursors induce allogeneic $\mathrm{T}$ cell hyporesponsiveness and prolong heart graft survival. Am J Transplant (2005) 5:1808-19. doi:10.1111/j.1600-6143.2005.00954.x

78. Lan YY, Wang Z, Raimondi G, Wu W, Colvin BL, DeCreus A, et al. "Alternatively-activated" dendritic cells preferentially secrete IL-10, expand Foxp $3^{+} \mathrm{CD} 4^{+} \mathrm{T}$ cells and induce long-term organ allograft survival in combination with CTLA4-Ig. J Immunol (2006) 177:5868-77. doi:10.4049/ jimmunol.177.9.5868

79. Turnquist H, Raimondi G, Zahorchak AF, Fischer RT, Wang Z, Thomson AW. Rapamycin-conditioned dendritic cells are poor stimulators of allogeneic $\mathrm{CD} 4^{+} \mathrm{T}$ cells, but enrich for antigen-specific Foxp $3^{+} \mathrm{T}$ regulatory cells and promote organ transplant tolerance. JImmunol (2007) 178:7018-31. doi:10.4049/jimmunol.178.11.7018

80. Lu L, McCaslin D, Starzl TE, Thomson AW. Bone marrow-derived dendritic cell progenitors (NLDC $145^{+}$, MHC class II', B7-1 dim, B7-2-) induce alloantigen-specific hyporesponsiveness in murine $\mathrm{T}$ lymphocytes. Transplantation (1995) 60:1539-45. doi:10.1097/00007890-199560120-00028

81. Macedo C, Walters JT, Orkis EA, Isse K, Elinoff BD, Fedorek SP, et al. Longterm effects of alemtuzumab on regulatory and memory T-cell subsets in kidney transplantation. Transplantation (2012) 93:813-21. doi:10.1097/ TP.0b013e318247a717

82. Lu L, Li W, Zhong C, Qian S, Fung JJ, Thomson AW, et al. Increased apoptosis of immunoreactive host cells and augmented donor leukocyte chimerism, not sustained inhibition of B7 molecule expression are associated with prolonged cardiac allograft survival in mice preconditioned with immature donor dendritic cells plus anti-CD40L mAb. Transplantation (1999) 68:747-57.

83. Wang Q, Zhang M, Ding G, Liu Y, Sun Y, Wang J, et al. Anti-ICAM-1 antibody and CTLA-4Ig synergistically enhance immature dendritic cells to induce donor-specific immune tolerance in vivo. Immunol Lett (2003) 90:33-42. doi:10.1016/S0165-2478(03)00160-3

84. Mirenda V, Berton I, Read J, Cook T, Smith J, Dorling A, et al. Modified dendritic cells coexpressing self and allogeneic major histocompatibility complex molecules: an efficient way to induce indirect pathway regulation. J Am Soc Nephrol (2004) 15:987-97. doi:10.1097/01.ASN.0000119575.98696.1D

85. DePaz HA, Oluwole OO, Adeyeri AO, Witkowski P, Jin MX, Hardy MA, et al. Immature rat myeloid dendritic cells generated in low-dose granulocyte macrophage-colony stimulating factor prolong donor-specific rat cardiac allograft survival. Transplantation (2003) 75:521-8. doi:10.1097/01. TP. $0000048380.84355 .4 \mathrm{~A}$

86. Hayamizu K, Huie P, Sibley RK, Strober S. Monocyte-derived dendriticcell precursors facilitate tolerance to heart allografts after total lymphoid irradiation. Transplantation (1998) 66:1285-91. doi:10.1097/00007890-199809150-00006

87. Adorini L, Penna G, Giarratana N, Uskokovic M. Tolerogenic dendritic cells induced by vitamin $\mathrm{D}$ receptor ligands enhance regulatory $\mathrm{T}$ cells inhibiting allograft rejection and autoimmune diseases. J Cell Biochem (2003) 88:227-33. doi:10.1002/jcb.10340

88. Eun SC, Baek RM, Park CG. Prolongation of the rat composite tissue allograft survival by the combination of tolerogenic immature dendritic cells and short-term treatment with FK506. Transplant Proc (2013) 45:1792-6. doi:10.1016/j.transproceed.2013.01.021

89. Valujskikh A, Lakkis FG. In remembrance of things past: memory $\mathrm{T}$ cells and transplant rejection. Immunol Rev (2003) 196:65-74. doi:10.1046/j.1600-065X.2003.00087.x

90. Bingaman AW, Farber DL. Memory T cells in transplantation: generation, function, and potential role in rejection. Am J Transplant (2004) 4:846-52. doi:10.1111/j.1600-6143.2004.00453.x

91. Nadazdin O, Boskovic S, Murakami T, Tocco G, Smith RN, Colvin RB, et al. Host alloreactive memory $\mathrm{T}$ cells influence tolerance to kidney allografts in nonhuman primates. Sci Transl Med (2011) 3:86ra51. doi:10.1126/ scitranslmed.3002093 
92. Gauzzi MC, Purificato C, Donato K, Jin Y, Wang L, Daniel KC, et al. Suppressive effect of 1alpha,25-dihydroxyvitamin D3 on type I IFN-mediated monocyte differentiation into dendritic cells: impairment of functional activities and chemotaxis. J Immunol (2005) 174:270-6. doi:10.4049/jimmunol.174.1.270

93. D’Ambrosio D, Cippitelli M, Cocciolo MG, Mazzeo D, Di Lucia P, Lang $\mathrm{R}$, et al. Inhibition of IL-12 production by 1,25-dihydroxyvitamin D3. Involvement of NF-kappaB downregulation in transcriptional repression of the p40 gene. J Clin Invest (1998) 101:252-62.

94. Steinbrink K, Wolfl M, Jonuleit H, Knop J, Enk AH. Induction of tolerance by IL-10-treated dendritic cells. J Immunol (1997) 159:4772-80.

95. Gordon JR, Ma Y, Churchman L, Gordon SA, Dawicki W. Regulatory dendritic cells for immunotherapy in immunologic diseases. Front Immunol (2014) 5:7. doi:10.3389/fimmu.2014.00007

96. Hutchinson JA, Riquelme P, Brem-Exner BG, Schulze M, Matthai M, Renders L, et al. Transplant acceptance-inducing cells as an immune-conditioning therapy in renal transplantation. Transpl Int (2008) 21:728-41. doi:10.1111/j.1432-2277.2008.00680.x

97. Hutchinson JA, Brem-Exner BG, Riquelme P, Roelen D, Schulze M, Ivens $\mathrm{K}$, et al. A cell-based approach to the minimization of immunosuppression in renal transplantation. Transpl Int (2008) 21:742-54. doi:10.1111/j.1432-2277.2008.00692.x

98. Hutchinson JA, Riquelme P, Sawitzki B, Tomiuk S, Miqueu P, Zuhayra $\mathrm{M}$, et al. Cutting Edge: immunological consequences and trafficking of human regulatory macrophages administered to renal transplant recipients. J Immunol (2011) 187:2072-8. doi:10.4049/jimmunol.1100762

99. Hutchinson JA, Riquelme P, Geissler EK, Fandrich F. Human regulatory macrophages. Methods Mol Biol (2011) 677:181-92. doi:10.1007/978-1-60761-869-0_13

100. Divito SJ, Ferris LK. Advances and short comings in the early diagnosis of melanoma. Melanoma Res (2010) 20:450-8. doi:10.1097/ CMR.0b013e32833faf7e

101. Penna G, Adorini L. 1 Alpha,25-dihydroxyvitamin D3 inhibits differentiation, maturation, activation, and survival of dendritic cells leading to impaired alloreactive T cell activation. J Immunol (2000) 164:2405-11. doi:10.4049/ jimmunol.164.5.2405

102. Hackstein H, Thomson AW. Dendritic cells: emerging pharmacological targets of immunosuppressive drugs. Nat Rev Immunol (2004) 4:24-35. doi: $10.1038 /$ nri1256

103. Scornik JC, Meier-Kriesche HU. Blood transfusions in organ transplant patients: mechanisms of sensitization and implications for prevention. Am J Transplant (2011) 11:1785-91. doi:10.1111/j.1600-6143.2011.03705.x
104. Anderson CB, Tyler JD, Sicard GA, Anderman CK, Rodey GE, Etheredge EE. Pretreatment of renal allograft recipients with immunosuppression and donor-specific blood. Transplantation (1984) 38:664-8. doi:10.1097/00007890-198412000-00023

105. Salvatierra O Jr, Melzer J, Potter D, Garovoy M, Vincenti F, Amend WJ, et al. A seven-year experience with donor-specific blood transfusions. Results and considerations for maximum efficacy. Transplantation (1985) 40:654-9. doi:10.1097/00007890-198512000-00016

106. Cheigh JS, Suthanthiran M, Fotino M, Riggio RR, Schechter N, Stubenbord WT, et al. Minimal sensitization and excellent renal allograft outcome following donor-specific blood transfusion with a short course of cyclosporine. Transplantation (1991) 51:378-81. doi:10.1097/00007890-199102000-00021

107. Lederer SR, Friedrich N, Banas B, Welser G, Albert ED, Sitter T. Effects of mycophenolate mofetil on donor-specific antibody formation in renal transplantation. Clin Transplant (2005) 19:168-74. doi:10.1111/j.1399-0012.2005.00261.x

108. Mehling A, Grabbe S, Voskort M, Schwarz T, Luger TA, Beissert S. Mycophenolate mofetil impairs the maturation and function of murine dendritic cells. JImmunol (2000) 165:2374-81. doi:10.4049/ jimmunol.165.5.2374

109. Lagaraine C, Hoarau C, Chabot V, Velge-Roussel F, Lebranchu Y. Mycophenolic acid-treated human dendritic cells have a mature migratory phenotype and inhibit allogeneic responses via direct and indirect pathways. Int Immunol (2005) 17:351-63. doi:10.1093/intimm/dxh215

110. Metes D, Logar A, Rudert WA, Zeevi A, Woodward J, Demetris AJ, et al. Four-color flow cytometric analysis of peripheral blood donor cell chimerism. Hum Immunol (2003) 64:787-95. doi:10.1016/ S0198-8859(03)00113-7

Conflict of Interest Statement: Angus W. Thomson is co-inventor of a US patent for generation of dendritic cells to enhance transplant tolerance. The remaining co authors declare that the research was conducted in the absence of any commercial or financial relationships that could be construed as a potential conflict of interest.

Copyright (c) 2016 Thomson, Zahorchak, Ezzelarab, Butterfield, Lakkis and Metes. This is an open-access article distributed under the terms of the Creative Commons Attribution License (CC BY). The use, distribution or reproduction in other forums is permitted, provided the original author(s) or licensor are credited and that the original publication in this journal is cited, in accordance with accepted academic practice. No use, distribution or reproduction is permitted which does not comply with these terms. 